\title{
ANALISIS PENGARUH KONFIGURASI EIGRP EQUAL DAN UNEQUAL COST LOAD BALANCING TERHADAP KINERJA ROUTER
}

\author{
Dian Bagus Saptonugroho, Dessyanto Boedi P. ,Budi Santosa \\ Program Studi Teknik Informatika, Fakultas Teknologi Industri \\ Universitas Pembangunan Nasional "Veteran" Yogyakarta \\ Jalan Babarsari No 2 Tambakbayan Yogyakarta \\ email : dess95@gmail.com
}

\begin{abstract}
Routing protocol is tasked with finding the best route to send the packet. Assessed using the metric. If there is more than one route with the same metric value, Routing Information Path (RIP), Open Shortest Path First (OSPF), and Enhanched Interior Gateway Routing Protocol (EIGRP) support equal cost load balancing to send packets to the destination. If there is more than one route with a different metric values, EIGRP can do unequal cost load balancing. Research needs to be conducted to determine the effect of the configuration of EIGRP equal and unequal cost load balancing on the performance of the router which can be used as a proof-of-concept testing that is part of the project design document on a network. Research networks using EIGRP as the routing protocol. After the equal and unequal load balancing is enabled by configuring the variance, CEF, per-destination load balancing, per-packet load balancing, or traffic sharing and analyzing its effect on the neighbor table, topology table, routing table, the data transmission, survivability, convergence, throughput, and utilization. This study used an emulator GNS3 as Cisco 2691 Router with Cisco IOS version 12:24 (25) c and advanced enterprise-adventerprisek9 image c2691-mz.124-25c.bin, and OPNET Modeler 14.5 for simulation. The results of the study can be used as a proof-of-concept testing in the design document for later use as contemplated in the manufacture of plan implementation and verification plan.
\end{abstract}

\section{Keyword: EIGRP, Cisco, Load Balancing}

Routing protocol bertugas mencari rute terbaik untuk mengirimkan paket. Rute dinilai menggunakan metric. Apabila terdapat lebih dari satu rute dengan nilai metric yang sama, Routing Information Path (RIP), Open Shortest Path First (OSPF), dan Enhanched Interior Gateway Routing Protocol (EIGRP) mendukung equal cost load balancing untuk mengirimkan paket ke tujuan. Jika terdapat lebih dari satu rute dengan nilai metric yang berbeda, EIGRP dapat melakukan unequal cost load balancing. Penelitian perlu dilakukan untuk mengetahui pengaruh konfigurasi EIGRP equal dan unequal cost load balancing terhadap kinerja router yang dapat digunakan sebagai proof-of-concept testing yang merupakan bagian dari design document pada suatu project jaringan. Penelitian membuat jaringan menggunakan EIGRP sebagai routing protocol. Setelah itu equal dan unequal load balancing diaktifkan dengan mengkonfigurasikan variance, CEF, per-destination load balancing, per-packet load balancing, atau traffic sharing serta menganalisis pengaruhnya terhadap neighbor table, topology table, routing table, rute pengiriman data, survivability, convergence, throughput, dan utilization. Penelitian ini menggunakan GNS3 sebagai emulator Cisco Router 2691 dengan Cisco IOS versi 12.24(25)c dan advanced enterprise image c2691-adventerprisek9-mz.124-25c.bin, serta OPNET Modeler 14.5 untuk simulasi. Hasil penelitian dapat digunakan sebagai proof-of-concept testing di dalam design document untuk selanjutnya digunakan sebagai bahan pertimbangan pembuatan implementation plan dan verification plan.

Keyword : EIGRP, Cisco, Load Balancing

\section{PENDAHULUAN}

Tugas sebuah routing protocol adalah mencari rute terbaik untuk mengirimkan data. Rute dinilai menggunakan metric. Rute terbaik adalah rute yang memiliki nilai metric terkecil. Jika ada dua atau lebih rute terbaik dengan nilai metric yang sama, maka router akan menggunakan semua rute tersebut untuk mengirimkan data kepada alamat tujuan. Fitur tersebut dinamakan 
equal cost load balancing. Routing protocol yang mendukung equal cost load balancing di antaranya adalah Routing Information Path (RIP), Enhanced Interior Gateway Routing Protocol (EIGRP), dan Open Shortest Path First (OSPF).

Dalam proses pencarian rute, bisa jadi routing protocol menemukan rute alternatif dengan nilai metric yang lebih besar dibandingkan dengan rute terbaik. Rute semacam ini dikelompokkan sebagai cadangan dan baru akan digunakan apabila rute terbaik tidak dapat dilewati. EIGRP dapat membuat router memanfaatkan semua rute, terlepas dari apakah rute itu yang terbaik dengan nilai metric terkecil maupun rute cadangan dengan nilai metric yang lebih besar. Semua rute tersebut dapat digunakan untuk mengirimkan data kepada alamat tujuan. Fitur tersebut dinamakan unequal cost load balancing. RIP dan OSPF tidak memiliki fitur unequal cost load balancing, sehingga fitur ini menjadi ekslusif milik EIGRP.

Berdasarkan dokumentasi dari Cisco, load balancing pada EIGRP dapat diatur dengan cara mengkonfigurasi variance, Cisco Express Forwarding (CEF), per-destination load balancing, per-packet load balancing, atau traffic sharing. Apakah EIGRP akan melakukan equal cost load balancing atau unequal cost load balancing bergantung pada konfigurasi variance, CEF, perdestination load balancing, per-packet load balancing, dan traffic sharing.

Kemampuan EIGRP melakukan equal dan unequal cost load balancing merupakan fitur yang tidak dimiliki oleh routing protocol seperti RIP dan OSPF sehingga penelitian perlu dilakukan untuk mengetahui pengaruh konfigurasi EIGRP equal dan unequal cost load balancing terhadap kinerja router.

Menurut Wendell Odom, tahap-tahap penyelesaian suatu project jaringan adalah membuat design document, menyusun implementation plan, dan membuat verification plan. Salah satu tugas network designers adalah mengumpulkan requirements dari internal dan eksternal customers, kemudian menerjemahkan requirements tersebut ke dalam network design, serta melakukan proof-of-concept testing. Penelitian mengenai pengaruh konfigurasi EIGRP equal dan unequal cost load balancing terhadap kinerja router ini dapat dijadikan sebagai proof-ofconcept testing pada saat pembuatan design document.

\section{STUDI PUSTAKA}

Tujuan dari penelitian berjudul Measuring Load-balanced Paths in the Internet adalah mengidentifikasi load balancing routers di internet dan mencari karakter dari jalur load balancing yang ditemukan. Penelitian ini menggunakan sebuah tool yang bernama Paris traceroute. Tool ini digunakan untuk mengukur jumlah jalur load-balanced yang ada di internet untuk yang pertama kalinya. Ditemukan data bahwa antara sumber dengan tujuan, 39\% merupakan perflow load balancer. Sedangkan $70 \%$ merupakan per-destination load balancer.

Tujuan dari penelitian berjudul Analisis dan Implementasi Load Balancing dan Failover serta Konfigurasi Alert pada PT Jasnita Telekomindo adalah mengimplementasikan load balancing, failover, dan alert pada gateway PT Jasnita Telekomindo menggunakan sistem operasi Mikrotik.

Pada penelitian berjudul Koneksi Internet Ganda dengan Load Balancing Menggunakan Unix Mikrotik pada PT. Marina Buana Asia, salah satu ISP yang tersedia digunakan untuk koneksi internasional, sedangkan ISP lainnya digunakan untuk koneksi lokal melalui static routing. Selain itu penelitian ini juga menerapkan failover secara manual untuk mengantisipasi koneksi internet jika terputus. Pemisahan koneksi internasional dengan koneksi lokal memberikan dampak positif meningkatnya kecepatan pengiriman data, upload data, serta download data.

Tujuan dari penelitian berjudul Analisis dan Pengujian Per-Packet Load Balancing pada Jaringan MPLS-VPN DS-TE di BPPT adalah mengimplementasikan per-packet load balancing pada jaringan testbed Pusat Teknologi Informasi dan Komunikasi (PTIK) yang merupakan salah satu unit kerja di lingkungan Badan Pengkajian dan Penerapan Teknologi (BPPT). Sistem yang sedang berjalan adalah MPLS VPN DiffServ-Aware Traffic Engineering. Penelitian berjudul Optimasi Jaringan Komputer Menggunakan Routing Protocol Open Shortest Path First (OSPF) dan Gateway Load Balancing Protocol (GLBP) pada BPPT dilakukan menggunakan software GNS3 berdasarkan topology milik Badan Pengkajian dan Penerapan Teknologi (BPPT). Penelitian ini menambahkan jalur redundant pada core router untuk mengantisipasi apabila terjadi kegagalan pada salah satu switch core. Routing protocol OSPF dikonfigurasikan pada setiap layer 3 switch yang terletak pada core layer disertai dengan fitur authentication untuk meningkatkan keamanan. Serta dilakukan perubahan routing protocol dari Hot Standby Routing Protocl (HSRP) menjadi Gateway Load Balancing Protocol (GLBP) pada distribution layer yang 
berdampak memberikan keseimbangan jaringan dalam pembagian jumlah host pada setiap forwarder switch, meminimalisir waktu apabila ada kegagalan pada switch aktif dalam meneruskan paket, dan dapat mengurangi packet loss jika terjadi kegagalan pada switch aktif tersebut.

Pada penelitian berjudul Perancangan dan Implementasi Jaringan Komputer Menggunakan Teknologi Load Balancing dan Failover pada PT. Aero Systems Indonesia, teknik failover digunakan untuk berpindah dari ISP satu ke ISP yang lainnya secara otomatis apabila ada gangguan pada ISP sebelumnya. Load balancing dilakukan menggunakan OpenBSD yang akan membagi trafik berdasarkan session. Jika session menuju ISP pertama penuh, maka session berikutnya akan menggunakan ISP yang lainnya. Selain sebagai load balancer, OpenBSD juga berfungsi sebagai failover. Ada 2 buah OpenBSD yang terhubung ke masing-masing ISP.

\section{HIPOTESIS}

Hipotesis yang akan dibuktikan pada penelitian ini adalah sebagai berikut:

i. Neighbor table tidak akan mengalami perubahan setelah konfigurasi variance, CEF, perdestination load balancing, per-packet load balancing, atau traffic sharing. Sedangkan topology table dan routing table akan mengalami perubahan setelah konfigurasi variance, CEF, per-destination load balancing, per-packet load balancing, atau traffic sharing.

ii. Rute pengiriman data akan berubah seiring dengan perubahan pada konfigurasi variance, CEF, per-destination load balancing, per-packet load balancing, atau traffic sharing.

iii. Survivability dan convergence pada router akan semakin baik setelah konfigurasi variance, CEF, per-destination load balancing, per-packet load balancing, atau traffic sharing.

iv. Throughput akan semakin besar setelah konfigurasi variance, CEF, per-destination load balancing, per-packet load balancing, atau traffic sharing. Sedangkan utilization akan semakin kecil setelah konfigurasi variance, CEF, per-destination load balancing, per-packet load balancing, atau traffic sharing.

v. Router yang menggunakan EIGRP equal atau unequal cost load balancing memiliki kinerja yang lebih baik dibandingkan dengan router yang tidak menggunakan EIGRP equal dan unequal cost load balancing.

\section{PERANCANGAN}

Poin-poin yang akan diteliti pada penelitian ini adalah sebagai berikut :

i. Cara mengkonfigurasi variance, CEF, per-destination load balancing, per-packet load balancing, atau traffic sharing.

ii. Perubahan yang terjadi pada neighbor table, topology table, dan routing table setelah konfigurasi variance, CEF, per-destination load balancing, per-packet load balancing, atau traffic sharing.

iii. Rute pengiriman data setelah konfigurasi variance, CEF, per-destination load balancing, perpacket load balancing, atau traffic sharing.

iv. Survivability dan convergence pada router setelah konfigurasi variance, CEF, per-destination load balancing, per-packet load balancing, atau traffic sharing.

$v$. Pengaruh variance, CEF, per-destination load balancing, per-packet load balancing, atau traffic sharing terhadap throughput dan utilization.

\subsection{Desain Jaringan}

Penelitian menggunakan 2 topology. Topology 1 dan topology 2 merupakan partial mesh. Topology 1 terdiri atas 5 buah router, sedangkan topology 2 terdiri atas 16 router.

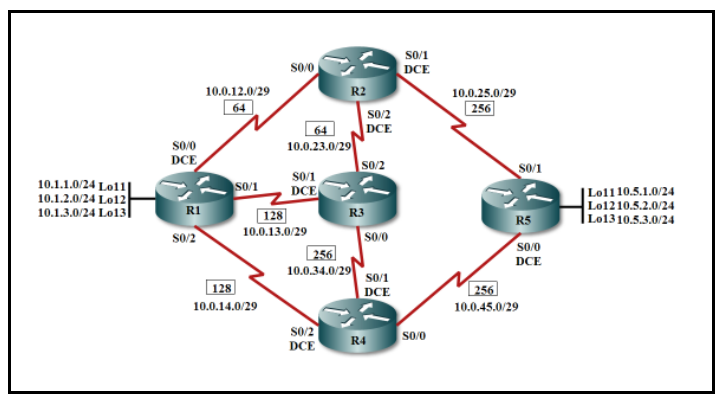




\section{Gambar 1. Topology 1}

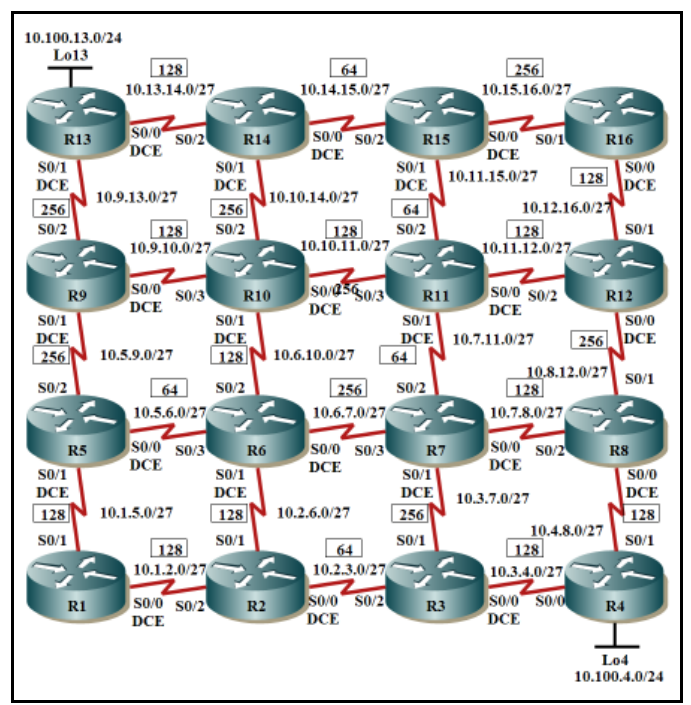

Gambar 2. Topology 2

Terdapat 9 skenario yang digunakan pada penelitian ini. Skenario 1, 2, 3, 4, dan 5 digunakan pada topology 1 . Sedangkan skenario $6,7,8$, dan 9 digunakan untuk topology 2.

Tabel 1. Skenario untuk topology 1

\begin{tabular}{|c|c|c|c|c|c|}
\hline Skenario & Skenario 1 & Skenario 2 & Skenario 3 & Skenario 4 & Skenario 5 \\
\hline Konfigurasi & default $(1)$ & default $(1)$ & default $(1)$ & 2 & 2 \\
\hline CEF & default (yes) & default (yes) & override & override & override \\
\hline per-destination load balancing & - & default (yes) & - & - & - \\
\hline per-packet load balancing & - & - & yes & yes & yes \\
\hline traffic sharing & - & - & balanced & min \\
\hline
\end{tabular}

Tabel 2. Skenario untuk topology 2

\begin{tabular}{|c|c|c|c|c|}
\hline $\begin{array}{lr}\text { Konfigurasi } & \text { Skenario } \\
\end{array}$ & Skenario 6 & Skenario 7 & Skenario 8 & Skenario 8 \\
\hline variance & default $(1)$ & default $(1)$ & 2 & 2 \\
\hline CEF & default (yes) & override & override & override \\
\hline per-destination load balancing & 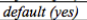 & & & \\
\hline per-packet load balancing & & yes & yes & yes \\
\hline traffic sharing & & & balanced & $\min$ \\
\hline
\end{tabular}

\subsection{Software yang Digunakan}

Ada 2 software jaringan yang digunakan pada penelitian ini, yaitu GNS3 dan OPNET Modeler 14.5.

GNS3 merupakan software yang menggunakan emulator Dynamips untuk menjalankan Cisco Internetwork Operating System (IOS). Cisco IOS merupakan sistem operasi yang digunakan pada Cisco routers. Pada penelitian ini router yang digunakan adalah Cisco Router 2691 dengan sistem operasi Cisco IOS versi 12.24(25)c dan advanced enterprise image c2691adventerprisek9-mz.124-25c.bin.

OPNET Modeler yang digunakan adalah versi 14.5. OPNET Modeler dipilih karena mampu memvisualisasikan rute pengiriman data, menguji survivablity, convergence, serta membandingkan throughput dan link utilization.

\section{PEMBAHASAN}

Pada topology 1, neighbor table milik router "R1" mencantumkan router "R2" (10.0.12.2), "R3" (10.0.13.3), dan "R4" (10.0.14.4) sebagai neighbor. Pada topology 2, neighbor table milik router "R4" mencantumkan router "R3" (10.3.4.3) dan router "R8" (10.4.8.8) sebagai neighbor. Daftar neighbor yang ada di dalam neighbor table pada kedua topology tidak berubah meskipun terdapat perubahan konfigurasi variance, CEF, per-destination load balancing, perpacket load balancing, dan traffic sharing. Hal ini karena neighbor harus reachable melalui Layer 2. Ditambah lagi, syarat untuk menjadi neighbor adalah router harus mampu mengirimkan atau menerima IP packets, alamat IP interface harus berada di subnet yang sama, tidak merupakan passive interface, harus memiliki ASN yang sama, harus lolos neighbor authentication (jika dikonfigurasikan), serta K-values harus cocok. Konfigurasi variance, CEF, per-destination load balancing, per-packet load balancing, dan traffic sharing tidak 
mempengaruhi faktor-faktor tersebut sehingga hubungan neighbor yang sudah dibentuk tidak berubah

Pada topology 1, topology table milik router "R1" menunjukkan bahwa EIGRP memilih router "R2" (10.0.12.2) dan router "R4" (10.0.14.4) sebagai Successor. Sedangkan router "R3" (10.0.13.3) dipilih sebagai Feasible Successor. Router "R2" (10.0.12.2) dan router "R4" (10.0.14.4) sebagai Successor memiliki nilai Feasible Distance sebesar 21152000. Router "R3" (10.1.3.3) memiliki nilai metric sebesar 21664000. Pada topology 2, topology table milik router "R4" menunjukkan bahwa EIGRP memilih router "R3" (10.3.4.3) dan router "R8" (10.4.8.8) sebagai Successor dengan nilai Feasible Distance sebesar 23200000. Router "R4" pada topology 2 tidak memiliki Feasible Successor. Topology table pada kedua topology tidak mengalami perubahan meskipun terdapat perubahan konfigurasi variance, CEF, per-destination load balancing, per-packet load balancing, atau traffic sharing.

Skenario 2 dan skenario 6 memiliki konfigurasi yang sama. Routing table pada skenario 2 menampilkan router "R2" (10.0.12.2) dan router "R4" (10.0.14.4) sebagai next hop untuk menuju subnet 10.5.1.0/24, 10.5.2.0/24, dan 10.5.3.0/24 milik router "R5". Sedangkan skenario 6 menampilkan router "R3" (10.3.4.3) dan router "R8" (10.4.8.8) sebagai next hop untuk menuju subnet 10.100.13.0/24 milik router "R13". Router "R2" (10.0.12.2) dan router "R4" (10.0.14.4) pada skenario 2 memiliki nilai metric sebesar 21152000. Router "R3" (10.3.4.3) dan router "R8" (10.4.8.8) pada skenario 6 memiliki nilai sebesar 23200000. Skenario 3 dan skenario 7 memiliki konfigurasi yang sama. Tidak ada perubahan pada isi routing table milik skenario 3 , isinya sama dengan routing table milik skenario 2 . Pada topology 2 , skenario 7 memiliki isi routing table yang sama dengan skenario 6 . Skenario 4 dan skenario 8 memiliki konfigurasi yang sama. Routing table pada skenario 4 menampilkan router "R2" (10.0.12.2), "R3" (10.0.13.3), dan "R4" (10.0.14.4) sebagai next hop untuk menuju subnet 10.5.1.0/24, 10.5.2.0/24, dan 10.5.3.0/24 milik router "R5". Router "R3" memiliki nilai metric yang lebih besar dibandingkan dengan router "R2" dan "R4", yaitu sebesar 21664000. Routing table pada skenario 8 menampilkan router "R3" (10.3.4.3) dan router "R8" (10.4.8.8) sebagai next hop untuk menuju subnet 10.100.13.0/24 milik router "R13". Skenario 5 dan skenario 9 memiliki konfigurasi yang sama. Skenario 5 memiliki isi routing table yang sama dengan skenario 4. Skenario 9 memiliki is routing table yang sama dengan skenario 6 , skenario 7 , dan skenario 8 . Dengan demikian routing table pada topology 1 menunjukkan perubahan seiring dengan perubahan konfigurasi variance.

Overhead atau additional memory akan semakin meningkat seiring dengan bertambahnya next hop yang dimasukkan ke dalam routing table. Pada topology 1, skenario 1 memiliki overhead yang berasal dari Route Source EIGRP sebesar 648 bytes. Skenario 2 dan skenario 3 memiliki overhead yang berasal dari Route Source EIGRP sebesar 864 bytes. Skenario 4 dan skenario 5 memiliki overhead yang berasal dari Route Source EIGRP sebesar 1440 bytes. Sedangkan overhead yang berasal dari Route Source connected besarnya tetap karena tidak ada penambahan next hop terhadap subnet yang terhubung langsung dengan router. Pada topology 2, skenario 6, 7, 8, dan 9 tidak mengalami peningkatan overhead yang berasal dari Route Source EIGRP karena tidak ada penambahan next hop untuk Route Source EIGRP maupun untuk Route Source yang lainnya. Sehingga besarnya overhead untuk Route Source EIGRP dan total overhead adalah tetap, yaitu sebesar 2736 bytes dan 2952 bytes.

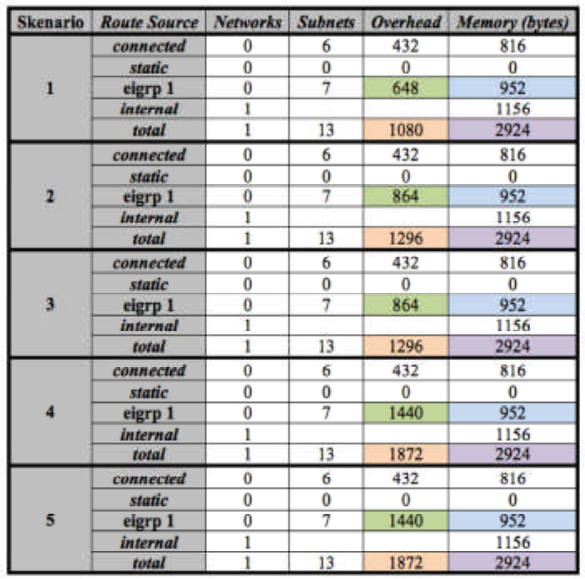

Gambar 3. Route summary pada topology 1 
Topology 1 mengalokasikan memory yang sama besar meskipun terdapat perubahan konfigurasi variance, CEF, per-destination load balancing, per-packet load balancing, atau traffic sharing. Pada topology 1, besar memory yang dialokasikan untuk Route Source EIGRP Autonomous System Number 1 adalah sebesar 952 bytes, sedangkan total memory yang dialokasikan adalah sebesar 2924 bytes. Topology 2 juga memiliki besar alokasi memory yang sama meskipun terdapat perubahan konfigurasi variance, CEF, per-destination load balancing, per-packet load balancing, dan traffic sharing. Pada topology 2, besar memory yang dialokasikan untuk Route Source EIGRP Autonomous System Number 2 adalah sebesar 3128 bytes, sedangkan total memory yang dialokasikan adalah sebesar 4692 bytes.

Hasil traceroute dan ping menunjukkan bahwa pada saat router "R1" memiliki 2 rute dengan nilai metric yang sama dan konfigurasinya dibiarkan default, maka router "R1" akan menggunakan 1 jalur saja untuk mengirimkan packet kepada alamat IP 10.5.1.1 yang terhubung dengan router "R5". Hal ini merupakan akibat dari CEF yang menggunakan perdestination load balancing. Setelah mematikan CEF atau dengan mengaktifkan per-packet load balancing, router akan menggunakan kedua rute secara simultan atau bersamaan untuk mengirimkan packet kepada alamat IP 10.5.1.1 yang terhubung dengan router "R5". Besarnya pembagian trafik yang digunakan oleh kedua rute adalah 1:1.

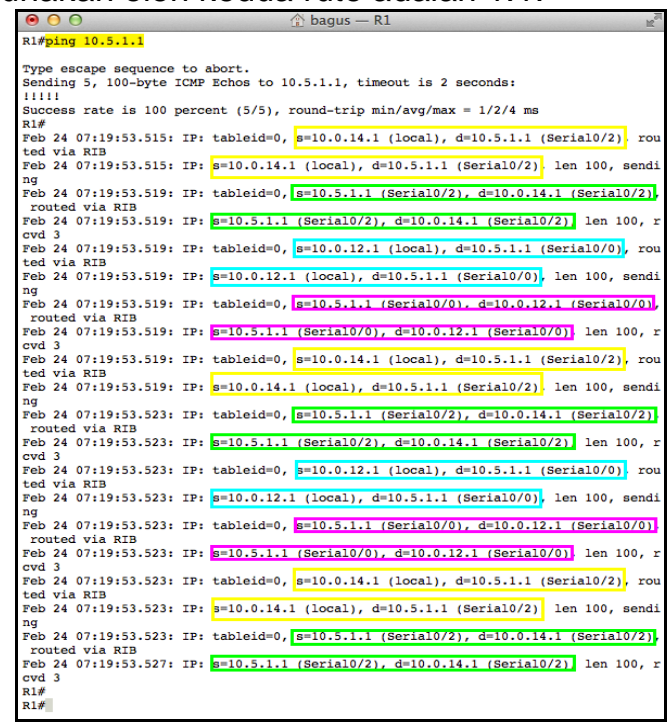

Gambar 4. Hasil ping pada skenario 3

Perubahan pada nilai variance mempengaruhi rute yang digunakan untuk pengiriman data. Setelah nilai variance diubah menjadi 2 dan parameter traffic sharing adalah "balanced", rute melalui router "R3" yang oleh router "R1" dikategorikan sebagai Feasible Successor dimasukkan ke dalam routing table dan digunakan untuk mengirimkan data kepada alamat IP 10.5.1.1 yang terhubung dengan router "R5". Besarnya pembagian trafik yang digunakan oleh rute $\mathrm{R} 2: \mathrm{R3}: \mathrm{R} 4$ adalah 40:39:40.

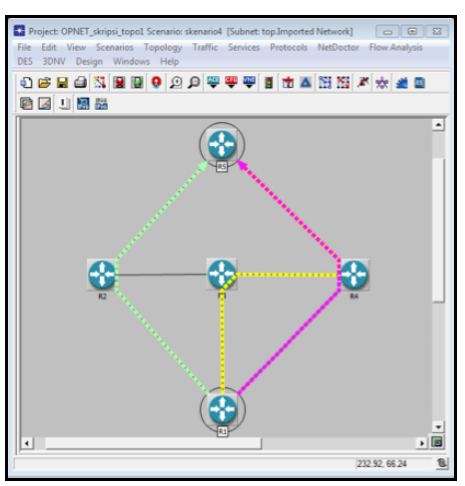

Gambar 5. Rute pengiriman data skenario 4

Pada saat nilai variance adalah 2 namun parameter traffic sharing diubah menjadi minimum, ternyata rute pengiriman data yang digunakan sama dengan pada saat konfigurasi 
menggunakan per-packet destination load balancing. Hanya rute dengan nilai metric terkecil yang digunakan untuk mengirimkan data, yaitu melalui router "R2" dan router "R3" karena keduanya memiliki nilai metric terkecil dan besarnya sama. Perbedaannya adalah dengan adanya nilai variance sebesar 2 , terdapat rute tambahan pada routing table melalui router "R3" meskipun rute ini tidak digunakan untuk mengirimkan data.

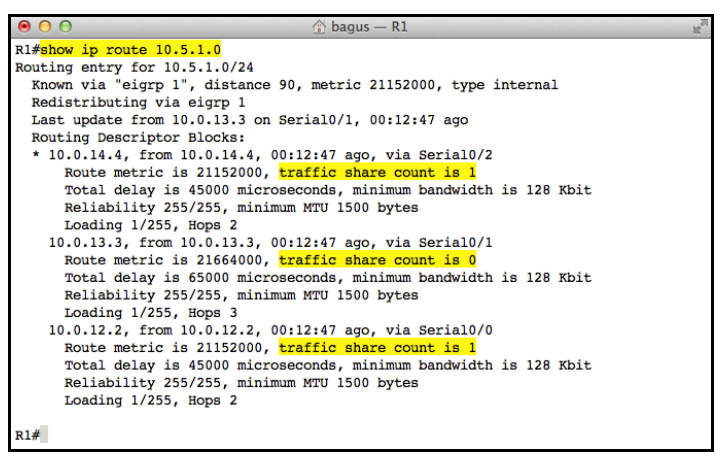

Gambar 6. Traffic Share Count milik router "R1" pada skenario 5

Karena rute melalui router "R3" tidak digunakan, maka perbandingan pembagian trafik R2:R3:R4 adalah 1:0:1. Sementara itu pada topology 2, seluruh skenario tidak memiliki perbedaan rute pengiriman data. Rute yang digunakan oleh router "R4" adalah tetap karena hanya terdapat 2 rute saja dengan nilai metric yang sama, sehingga perubahan konfigurasi variance, CEF, per-destination load balancing, per-packet load balancing, atau traffic sharing tidak memberikan dampak pada topology 2.

Pada saat terjadi failure link R1-R4 pada topology 1, router "R1" sudah memiliki alternatif rute pengiriman data tanpa harus memilih Feasible Successor menjadi Successor karena adanya 2 Successor dengan nilai metric yang sama. Konfigurasi variance bahkan dapat memasukkan next hop tambahan ke dalam routing table sehingga alternatif rute pengiriman data menjadi bertambah lagi melalui router "R3". Di antara skenario 2, 3, 4, dan 5, nilai baseline delay yang paling kecil dimiliki oleh skenario 2 , yaitu 6,6 $\mathrm{ms}$. Nilai baseline delay yang paling besar dimiliki oleh skenario 4 dan skenario 5 , yaitu $8,5 \mathrm{~ms}$. Nilai failure delay yang paling kecil dimiliki oleh skenario 4 dan skenario 5 , yaitu $9 \mathrm{~ms}$. Nilai failure delay yang paling besar dimiliki oleh skenario 3, yaitu 12,4 ms. Delay difference yang paling kecil dimiliki oleh skenario 4 dan skenario 5, yaitu 5\%. Delay difference paling besar dimiliki oleh skenario 3, yaitu 79\%. Apabila skenario 1 diikutsertakan dalam perbandingan, skenario 1 memiliki baseline delay yang paling besar. Sedangkan nilai failure delay-nya hanya kalah besar dibandingkan dengan skenario 3 , yaitu 11,6 ms untuk skenario 1 dan 12,4 ms untuk skenario 3. Delay difference milik skenario 1 adalah sebesar $24 \%$. Nilai ini lebih kecil daripada delay difference milik skenario 2 dan skenario 3 , yaitu berturut-turut $41 \%$ dan $79 \%$. Topology 2 memiliki baseline delay dan failure delay yang lebih besar dibandingkan dengan topology 1 .

Average route convergence duration yang paling kecil dimiliki oleh skenario 3 . Nilai tersebut lebih kecil dibandingkan dengan skenario 1 yang tidak menggunakan equal dan unequal cost load balancing. Skenario 1 memiliki average route convergence duration yang paling besar. Meskipun begitu perbedaannya ada pada 10-5 detik sehingga selisinnya tidak begitu signifikan.

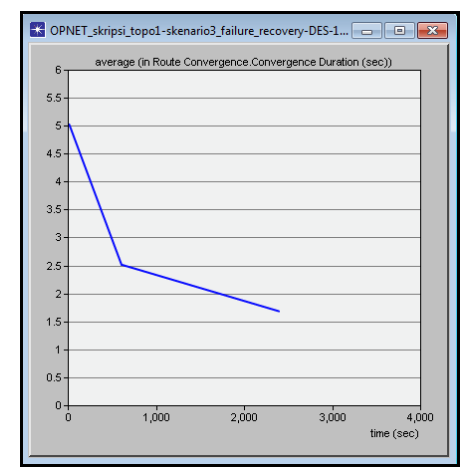

Gambar 7. Average route convergence duration router "R1" pada skenario 3 
Nilai throughput paling rendah dimiliki oleh skenario 4. Pengiriman data pada skenario 4 didistribusikan menggunakan ketiga rute yang tersedia pada routing table, yaitu melalui router "R3", "R4", dan "R5". Adanya pembagian trafik ini menyebabkan nilai throughput skenario 4 menjadi lebih rendah dibandingkan dengan skenario lainnya. Apabila dibandingkan dengan skenario 1 yang tidak menggunakan equal dan unequal cost load balancing, nilai throughputnya adalah yang paling besar karena hanya menggunakan 1 rute untuk mengirimkan data kepada alamat IP 10.5.1.1/24 yang terhubung dengan router "R5".

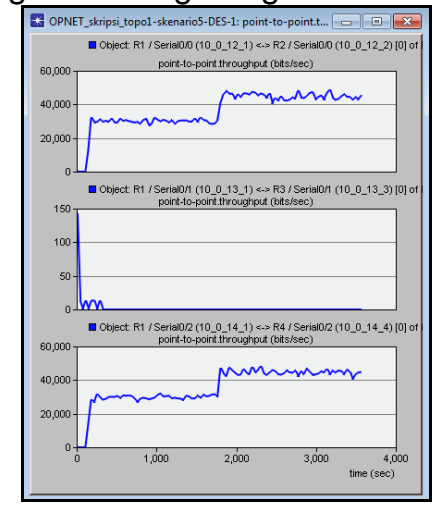

Gambar 8. Throughput link R1-R2 (atas), link R1-R3 (tengah), dan link R1-R4 (bawah) pada skenario 5

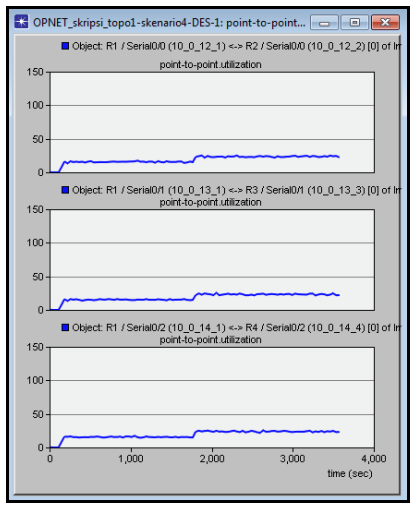

Gambar 9. Utilization link R1-R2 (atas), link R1-R3 (tengah), dan link R1-R4 (bawah) pada skenario 4

Pada topology 1, pada saat mengirimkan data kepada alamat IP 10.5.1.1/24 yang terhubung dengan router "R5", nilai utilization yang paling tinggi dimiliki oleh skenario 2. Sebabnya adalah skenario 2 hanya menggunakan 1 rute, sehingga konsumsi bandwidth pada link yang digunakan untuk mengirimkan data mencapai 56,205\%. Nilai utilization paling rendah dimiliki oleh skenario 4. Sebabnya adalah router "R1" pada skenario 4 menggunakan 3 rute sekaligus. Konsumsi bandwidth pada link yang sama dengan skenario 2, pada skenario 4 besarnya adalah 18,994\%.

\section{UJI HIPOTESIS}

Routing table pada topology 1 dan topology 2 menunjukkan perubahan seiring dengan perubahan konfigurasi variance. Overhead yang dialokasikan untuk Route Source EIGRP juga akan semakin meningkat seiring dengan perubahan konfigurasi variance karena adanya rute tambahan yang memenuhi syarat untuk masuk ke dalam routing table. Sedangkan besar alokasi memory untuk Route Source EIGRP adalah tetap.

Pada saat router memiliki 2 rute dengan nilai metric yang sama, sementara konfigurasi dibiarkan default, maka router akan menggunakan 1 jalur saja untuk mengirimkan data kepada suatu alamat tujuan. Hal ini merupakan akibat dari CEF yang menggunakan per-destination load balancing. Setelah mematikan CEF atau dengan mengaktifkan per-packet load balancing, router akan menggunakan kedua rute secara simultan atau bersamaan untuk mengirimkan data. Besarnya pembagian trafik yang digunakan oleh rute tersebut adalah sama. Perubahan nilai variance mempengaruhi rute yang digunakan untuk pengiriman data. Apabila nilai variance 
dikalikan dengan nilai Feasible Distance lebih besar daripada nilai metric untuk menuju alamat tujuan milik Feasible Successor, maka Feasible Successor tersebut akan dimasukkan ke dalam routing table. Besarnya pembagian trafik yang digunakan adalah sesuai dengan besarnya metric. Pada saat parameter traffic sharing diubah menjadi minimum, ternyata hanya rute dengan nilai metric terkecil yang digunakan untuk mengirimkan data. Perbedaannya adalah terdapat rute tambahan dengan nilai metric yang lebih besar pada routing table. Namun rute tambahan ini tidak digunakan untuk mengirimkan data karena memiliki traffic share count dengan nilai 0 .

Skenario 2 yang menggunakan konfigurasi default memiliki baseline delay yang paling kecil. Sedangkan baseline delay paling besar ada pada skenario 1 yang tidak menggunakan equal dan unequal cost load balancing. Failure delay paling kecil ada pada skenario 4 dan skenario 5 yang juga memiliki delay difference paling kecil. Failure delay yang paling besar dimiliki oleh skenario 3. Delay difference yang paling besar ada pada skenario 3. Semakin besar jaringan, maka akan semakin besar nilai baseline delay dan failure delay. Average route convergence duration paling kecil dimiliki oleh router yang menggunakan per-packet load balancing dan traffic sharing dengan parameter balanced. Sedangkan average route convergence duration yang paling besar dimiliki oleh skenario 1 yang tidak menggunakan equal dan unequal cost load balancing.

Nilai throughput dan utilization pada router yang menggunakan lebih dari 1 rute untuk mengirimkan data kepada alamat tujuan adalah lebih kecil dibandingkan dengan nilai throughput dan utilization pada router yang hanya menggunakan 1 rute. Penyebabnya adalah karena trafik didistribusikan kepada rute-rute yang ada sesuai dengan rasio masing-masing rute tersebut.

\section{KESIMPULAN}

Kesimpulan yang dapat diambil dari penelitian ini adalah sebagai berikut :

i. Telah selesai dilaksanakan penelitian mengenai pengaruh konfigurasi EIGRP equal dan unequal cost load balancing terhadap kinerja router.

ii. Hasil penelitian dapat digunakan sebagai proof-of-concept testing di dalam design document untuk selanjutnya digunakan sebagai bahan pertimbangan pembuatan implementation plan dan verification plan.

iii. Keuntungan atau kelebihan dari penggunaan EIGRP equal dan unequal cost load balancing adalah adanya lebih dari 1 successors dan adanya Feasible Successors pada topology table menyebabkan router tidak perlu melakukan komputasi ulang menggunakan DUAL pada saat terjadi failure pada salah satu next hop yang tersedia. Nilai baseline delay, failure delay, dan delay difference lebih kecil pada router yang menggunakan EIGRP equal dan unequal cost load balancing daripada router yang tidak menggunakan EIGRP equal dan unequal cost load balancing. Average route convergence duration lebih cepat pada router yang menggunakan EIGRP equal dan unequal cost load balancing daripada router yang tidak menggunakan EIGRP equal dan unequal cost load balancing. Semakin banyak rute yang digunakan maka akan semakin kecil throughput dan utilization pada suatu link. Hal yang harus diperhatikan dari penggunaan equal dan unequal cost load balancing adalah semakin banyak rute yang dimasukkan ke dalam routing table, akan semakin besar overhead atau additional memory yang dialokasikan. Router yang menggunakan per-packet load balancing memiliki delay yang lebih besar dibandingkan router yang menggunakan per-destination load balancing dengan konfigurasi yang sama.

\section{SARAN}

Hal-hal berikut ini dapat dijadikan sebagai bahan pertimbangan untuk menghasilkan penelitian yang lebih baik dengan topik atau bidang yang sejenis.

i. Penelitian ini merupakan simulasi dan dibuat menggunakan software GNS3 dan OPNET Modeler. Alangkah baiknya apabila penelitian serupa dilakukan menggunakan peralatan jaringan yang sebenarnya.

ii. Penelitian yang akan datang sebaiknya melakukan studi kasus pada jaringan yang telah berjalan sehingga berdasarkan topology dan karakteristik jaringan yang sebenarnya.

iii. OPNET Modeler 14.5 masih memiliki kekurangan yaitu tetap memasukkan rute yang bukan merupakan Feasible Successor ke dalam routing table setelah konfigurasi variance. Diharapkan OPNET Modeler dapat memperbaiki kekurangan ini pada versi selanjutnya.

aDAFTAR PUSTAKA 


\section{DAFTAR PUSTAKA}

Augustin, Brice \& Friedman, Timur \& Teixeira, Renata. Measuring Load-balanced Paths in the Internet. Laboratoire d'Informatique de Paris 6 (LIP6), Université Pierre et Marie Curie and CNRS.

Cisco. How Does Unequal Cost Path Load Balancing (Variance) Work in IGRP and EIGRP?. Cisco Documentation.

Gunawan, Harry \& Prakoso, Jeffry Hutomo. 2012. Analisis dan Pengujian Per-Packet Load Balancing pada Jaringan MPLS-VPN DS-TE di BPPT. Universitas Bina Nusantara.

Hendarto, Alam Dari \& Febryan, Hendarsyah \& Romadhon, Dimas Ganjar. 2009. Koneksi Internet Ganda dengan Load Balancing Menggunakan Unix Mikrotik pada PT. Marina Buana Asia. Universitas Bina Nusantara.

Johnson, Allan. 2008. 31 Days Before Your CCNA Exam. USA: Cisco Press.

Kothari, C. R. 2004. Research Methodology - Methods \& Techniques. India: New Age International Publishers.

Kumala, Cindy Putri \& Vanessa, Mergi \& Holimdari, Yolan. 2009. Analisis dan Implementasi Load Balancing dan Failover serta Konfigurasi Alert pada PT Jasnita Telekomindo. Universitas Bina Nusantara.

Nugroho, Rachmad \& Prayetno, Andri \& Ningsih, Lina Wardiya. 2010. Optimasi Jaringan Komputer Menggunakan Routing Protocol Open Shortest Path First (OSPF) dan Gateway Load Balancing Protocol (GLBP) pada BPPT. Universitas Bina Nusantara.

Odom, Wendell. 2010. CCNP ROUTE 642-902 Official Certification Guide. USA: Cisco Press.

OPNET. 2008. Modeler Documentation. OPNET Documentation.

Prasetyo, Andika Budi \& Pratama, Adhithya Rizki \& Istira Yudha. 2012. Perancangan dan Implementasi Jaringan Komputer Menggunakan Teknologi Load Balancing dan Failover pada PT. Aero Systems Indonesia. Universitas Bina Nusantara.

Stringfield, Nakia \& White, Russ \& McKee, Stacia. 2007. Cisco Express Forwarding. USA: Cisco Press.

Teare, Diane. 2010. Implementing Cisco IP Routing (ROUTE) Foundation Learning Guide. USA: Cisco Press. , <http://faxswitch.com/Definitions/telecom dictionary n.html>, (diakses 18 November 2013) 